\title{
Health promotion for young patients with haemophilia
}

\section{Counselling, adjuvant exercise therapy and school sports}

\author{
Judith Sondermann ${ }^{1 *}$; Marco Herbsleb ${ }^{1 *}$; Frank-Detlef Stanek2; Holger Gabriel'; \\ Karim Kentouche ${ }^{3}$ \\ ${ }^{1}$ Department of Sports Medicine, Friedrich-Schiller-University of Jena, Germany; ${ }^{2} \mathrm{GP}$ 's surgery, Jena, Germany; \\ ${ }^{3}$ Clinic for children and youth medicine, University Hospital, Jena, Germany
}

\begin{abstract}
Keywords
Haemophilia, exercise therapy, self-competence, health counselling

\section{Summary}

The haemophilia treatment centre of the Clinic for Children and Youth Medicine in Jena extends medical care by health-promotion measures, namely: health counselling, adjuvant exercise therapy and school sports. In addition to the regular medical checks at the treatment centre patients are examined regarding physical fitness, joint situation, quality of life in general and disease-specific manner, as well as psycho-social and nutritional behaviour. Findings and medical results of the examinations are integrated into an individual advice on therapy, school
\end{abstract}

Korrespondenzadresse

Dr. Marco Herbsleb

Department of Sports Medicine and Health Promotion

Friedrich-Schiller-University of Jena

Wöllnitzer Street 42, 07749 Jena, Germany

Tel. 036 41/94 56 63, Fax 036 41/94 5652

E-mail:marco.herbsleb@uni-jena.de

* These authors contributed equally to this study. sports, and health recommendations. This aimed at strengthening health-related resources and minimizing potential injuries. First long-term evaluation shows an increase of activity behaviour and physical fitness without increasing bleeding rate and maintained joint function. Conclusion: Combining functional prevention diagnostics and individual health counselling shows signs of improved patient's health knowledge, self-competence and physical fitness.

\section{Schlüsselwörter}

Hämophilie, Bewegungstherapie, Selbstkompetenz, Gesundheitsberatung

Gesundheitsförderung für Kinder und Jugendliche mit Hämophilie

Gesundheitsberatung, adjuvante Bewegungs-

therapie und Schulsport

Haemostaseologie 2017; 37: 107-116

http://dx.doi.org/10.5482/HAM0-15-02-0007

received: February 20, 2015

accepted in revised form: June 2, 2016

epub ahead of print: June 15, 2016

Funding

The project is supported by Baxter Germany GmbH

\section{Zusammenfassung}

Das Behandlungskonzept am Hämophilie-Behandlungszentrum der Kinder- und Jugendklinik in Jena wurde um gesundheitsförderliche Maßnahmen der Gesundheitsberatung, adjuvanten Bewegungstherapie und des Schulsports erweitert. Begleitend zur turnusmäßigen Untersuchung werden Patienten zusätzlich hinsichtlich körperlicher Leistungsfähigkeit, aktueller Gelenksituation, allgemeiner und krankheitsspezifischer Lebensqualität sowie psychosozialen Verhaltens untersucht. Ferner wird das Ernährungsverhalten der Patienten erfasst und eine befundbasierte Gesundheitsberatung angeboten. Die Ergebnisse fließen zusammen mit den klinischen Befunden in individuelle Therapie-, Schulsport- und Gesundheitsempfehlungen ein. Eine erste Längsschnittauswertung weist auf eine Zunahme des Aktivitätsverhaltens und der körperlichen Leistungsfähigkeit bei gleichzeitig stabiler Blutungsrate und Erhaltung der Gelenkfunktion hin. Schlussfolgerung: Die Kombination von funktioneller Präventionsdiagnostik und individueller Gesundheitsberatung mit besonderer Förderung des Gesundheitswissens, der Selbstkompetenz und der körperlichen Aktivität haben sich bislang bewährt.
Health is a fundamental source for achieving other goals in life. That is why health promotion aims to help people achieving a successful life by improving their quality of life. Successful health promotion for persons with haemophilia requires attention to the specific impaired functions, as well as the associated disabilities $(1,2)$.

Although individuals with haemophilia require specific therapy due to the precon- ditions of a genetic disease, they also require specific prevention from pathological consequences and specific promotion of health resources. At the same time, stigmatization like segregation or exclusion must be avoided. Health promotion for persons with haemophilia includes disease prevention as behavioural prevention and situational prevention. Because of musculoskeletal bleedings, parental overprotec- tion and exclusion from school sports children and adolescents with haemophilia suffer from a lack of physical activity and monotony of physical activities in leisure time as well as in school. There exists unsureness along many teachers how to include young haemophiliacs in their sport lessons often resulting in complete exclusion from school sports disciplines or whole lessons. The ways in which the 
family, tutors and peers act towards the young patients leads to generally too little physical activity. Diminution of the physical activities impacts also emotional and social dimensions, thus effecting general health and well-being.

The negative effects of inactivity on organ function are becoming increasingly noticed. A lack of physical activity and the associated reduced physical performance capacity is considered an evident risk factor for developing cardiovascular disease or non-insulin-dependent diabetes mellitus $(3,4)$. In addition, epidemiological studies have unmistakably revealed a dose-dependent association between physical activity and a reduced overall mortality as well as an important role in the prevention and rehabilitation from coronary heart disease, atherosclerosis, overweight, elevated blood pressure and elevated cholesterol level (5). This becomes even more significant considering that persons with haemophilia have a greater risk of obesity because of inactivity due to musculoskeletal bleedings and overprotection (6). Currently children with haemophilia have almost the same life expectancy compared to unaffected children. Increased longevity may lead to complex medical problems that up to now have rarely been observed in haemophilia patients. Obesity will aggravate the disease burden of haemophilia in the elderly persons (7). Furthermore, persons with haemophilia may show the same or even a higher risk for old-age cardiovascular and oncological diseases than the general population (8).

For many years, experts have recommended sports and regular physical activity in the adjuvant treatment of persons with haemophilia $(9,10)$. The results from some recent studies state, that haemophilic children and adolescents today in the western world will adopt a comparable physically active lifestyle to healthy people - depending on joint condition, physical function and, inverse correlated, parental overprotection $(11,12)$. Especially in haemophilic children, who still have a good joint condition, that allows normal activity or only minimal limitations, basic motor skills are progressively aligned to the physical capacity of their age matched peers $(6,13)$. Despite this positive trend, the majority of

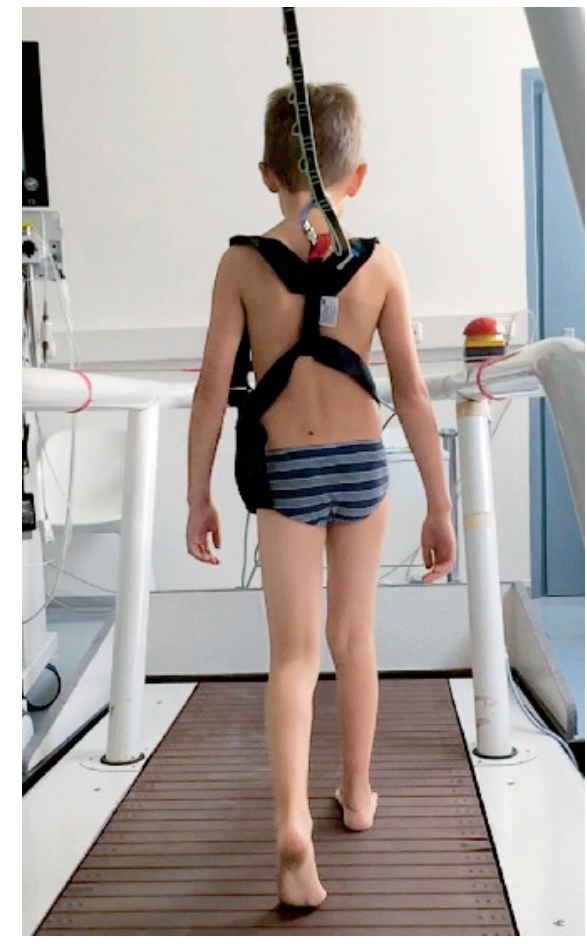

Fig. 1 Young patient on the treadmill during Global-Gait-Analysis as one part of the HJHS.

children and adolescents with haemophilia show already existing functional deficits both in physical capacity and in joint condition at an early stage $(11,14,15)$.

\section{Aims}

Health promoting activities consider both genetically caused impaired physical functioning and the associated ability to deal with the impairment. A professional team of the sport medical profession developed a health promotion concept based on health theories to contribute to the normal development of children and adolescents with haemophilia despite the obstacles of their diseases by reinforcing health resources and minimizing the consequences of disease. The aim is to enable children and adolescents with their parents to practice health-promoting behaviour independently and with a sense of responsibility. The specific aims are:

1. Functional preventive diagnostics with the aim of health counselling and movement therapy
2. Improvement of knowledge of health and of self-competence through health counselling and health education.

The primary endpoints of the longitudinal study are

- improvement or maintenance of joint function (Haemophilia Joint Health Score),

- maintenance or reduction of the bleeding rate (annual bleeding rate),

- improvement of individual physical performance capacity (spiroergometry, maximum strength measurement, posturography).

The secondary endpoints are

- improvement of the general quality of life and of the disease-specific quality of life (KINDL, HaemoQoL),

- an increase in physical activity (Proxy or self-report),

- improvement of physical resources with the goal of enhancing psychosocial behaviour (SDQ).

\section{Patients, methods}

\section{Study design and patients}

The study was designed as prospective, non-randomized trial. Children and adolescents with haemophilia A and B in the group aged from 5 to 18 , predominantly from the treatment centre in Jena, were examined with respect to their physical performance capacity, joint situation, health behaviour, and behavioural disorders. All of the patient examinations took place in Jena at the Department of Sports Medicine and Health Promotion and in the haematological outpatient department of the Clinic for Children and Youth Medicine.

The patients were examined once a year, every ten to twelve months. This was also the interval to assess the outcome.

Informed consent of the participants or their legal representative was obtained at the treatment centre together with their clinical examination and assessment of physical fitness.

The clinical results were reported to the Department of Sports Medicine in advance to the sports medical examination and consultation. Questionnaires to reflect the 


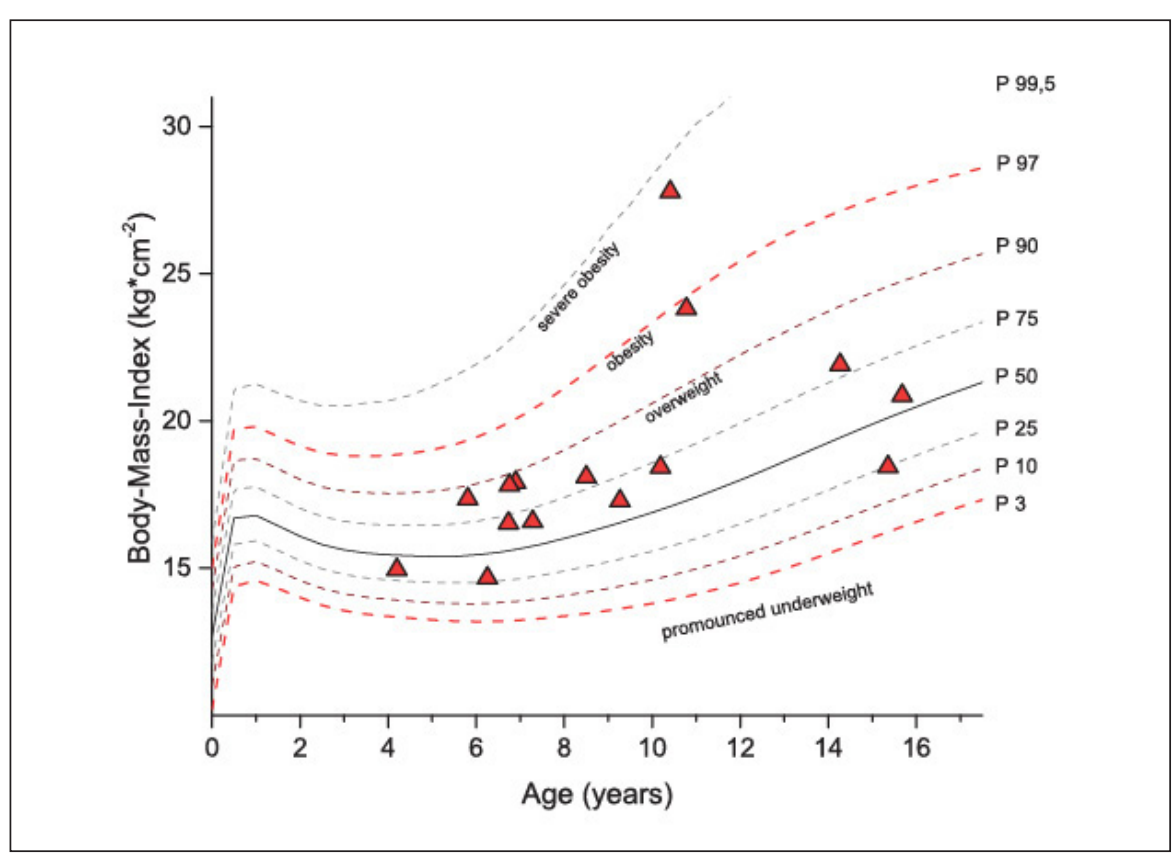

Fig. 2 Age and body mass index (BMI) of the patients examined. The dashed lines characterize the BMI-percentiles of German children and adolescents (17).

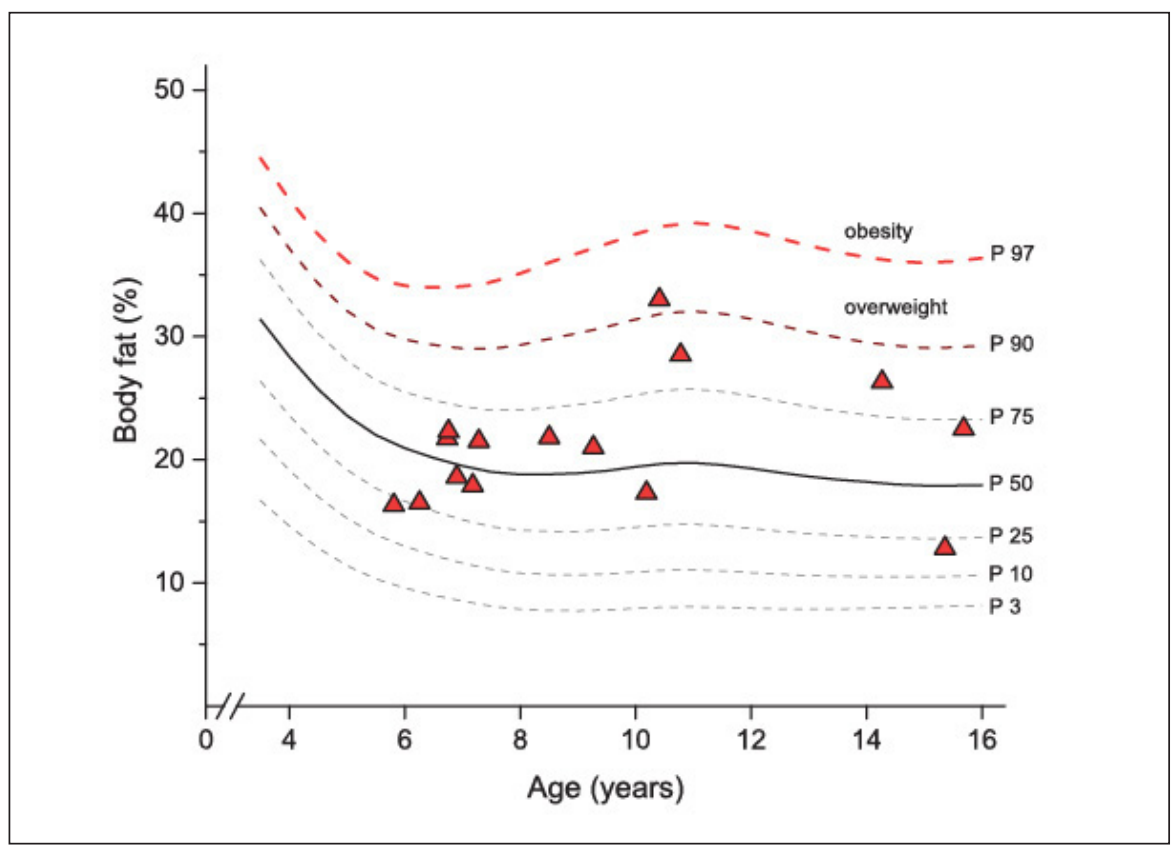

Fig. 3 Body fat (\%) of the patients examined in relation with reference percentiles of German children and adolescents according to Plachta-Danielzik et al. (16). The $90^{\text {th }}$ (brown) and $97^{\text {th }}$ (red) percentile represent the cut-off-lines for defining overweight and obesity.

patient's quality of life and behaviour are already completed at home. That ensured a higher quality of the response and efficacy at the examination day.
On the basis of the results from the clinical and sports medical examinations an individual report was created to give recommendations on physical activity as well as specific guidelines for physical education at school. If appropriate therapeutic exercises were taught and dietary advice offered.

\section{Methods of measurement}

In the following section, the diagnostic tools are described in a short overview.

\section{Anthropometric data}

Body mass ( Fig. 2), body height and skinfold thickness ( $\triangleright$ Fig. 3 ) are measured and classified by the use of current regional percentile curves for 7 to 14 year-old children and adolescents from Jena (16) and the data recorded Germany-wide for 8 to 18 year-olds of the Robert-Koch Institute (17). Reference percentiles are used to calculate standard deviation scores (SDS) of the subjects that were examined $(17,18)$.

\section{Assessment of joint health}

Version 2.1 of the Haemophilia Joint Health Score (HJHS) is used to measure the joint situation (19) as one of the primary endpoints of this study. The HJHS is an examination score of the six most frequently affected joints which is subdivided for 4 to 18 year-old children and adolescents with haemophilia: of the ankle, knee and elbow joints. It is a measuring tool with 11 items (swelling, duration of the swelling, muscular atrophy, axial deviation, crepitation, loss of flexion and extension, instability, joint pain, strength and gait) recorded separately for each of the six joints. The "Global Gait Score" Fig. 1) is used to rate the skills of walking, climbing stairs, running and jumping on one leg as being within or without the physiological limits. The sum of all scores yields an HJHS scale of 0 to 124 , where a score of 124 indicates maximum joint damage and impairment of all six joints. A score of 0 to 6 (according to version 1.0) is rated as being normal (19). A high rate of inter-rater and intra-rater reliability (20) and validity (19) has been shown for the HJHS-Version 1.0.

\section{Posturography}

Static posturography as a measurement of balance when combined with a gait analysis can help to objectify gait disorders and 
an unsteady standing position ( $\$$ Fig. 4). This allows for differentiated measurement and recording of the vertical forces of the forefoot and hind foot along with registration of the interaction of the forces. A posturographic examination in eight standardized test positions (Tetrax-Interactive Balance System, IBS, Neurodata, Vienna) and a one-leg stand test were carried out as primary measuring methods on the examination day to assess posture control and balance (21). The Stability Index (ST) is determined. The ST represents a four-dimensional non-unit vector of the changes in vertical forces of each of the four Tetrax plates, averaged over the experimental time and normalized to body mass. It is calculated as the square root of the sum of the squared differences between adjacent pressure fluctuation signals, sampled at a rate of $32 \mathrm{~Hz}$. In this way, it provides information on the general (postural) stability. The higher the score, the greater the sway and instability. Several research groups (22, 23) have shown significant deficits in the static balance skills of adult patients with haemophilia in comparison with healthy controls, verified with the one-leg stand test. Others $(24,25)$ have come to similar conclusions for haemophilic children through descriptive analysis of normal values. The examination is conducted with patients older than six years to ensure the concentration and patience required to finish the posturography examination. Agespecific reference values are used for interpretation (26).

\section{Maximum strength measurement}

Isometric maximum strengths $\left(\mathrm{m}^{3}\right.$ diagnos; SCHNELL $^{\circ}$ ) of the knee extensors and knee flexors under static testing conditions are measured and reported - separately for the left and right leg. Further details concerning methodological aspects of strength measurements may be found in earlier work (27).

\section{Spiroergometry}

A maximal graded cardiopulmonary exercise test on a cycle ergometer according to the Godfrey protocol is performed (28) to record a possible improvement of individual physical performance capacity. After 5



Fig. 4 Stability index (ST) averaged over all testing positions of the posturographic examination. The dashed lines represents age and gender-specific reference percentiles (26).

minutes resting period, participants begin exercise testing by 3 -min of unloaded cycling ("OW"). Power output is then increased in constant increments of 10,15 , or 20 watts every minute, depending on the patients' body height and in some conditions is adjusted for the expected physical condition of the patient. Heart rate is continuously recorded throughout the test. After maximal exercise is reached, a cooling down phase is performed consisting of 3 min pedalling at a slow rate $(<40$ revolutions/min) at a power output of $5 \mathrm{~W}$ and $7 \mathrm{~min}$ of quiet sitting. During the resting period, the exercise test, and recovery phase ventilatory indices and gas exchanges are measured continuously on a breath-by-breath basis using an automatic spirometer. The achieved peak oxygen uptake $\left(\mathrm{VO}_{2 \text { peak }}\right)$ and peak power output $\left(\mathrm{P}_{\text {peak }}\right)$ along with the recovery behaviour are assessed using current age-based reference values for children and adolescents (29, > Fig. 5). The following submaximal exercise parameters are also determined as target parameters for assessing cardiopulmonary capacity and efficiency: Ventilatory Threshold, Oxygen Uptake Efficiency Slope, and Ventilatory Efficiency. In contrast to the case of peak parameters, the determination of these submaximal pa- rameters offers the great advantage that maximal effort and motivation in patients are not mandatory. Contemporary age and gender specific reference values with lower 95\% confidence limits from a European cross-sectional population study are used to classify $\mathrm{VT}_{1}$ and $\mathrm{VO}_{2 \text { peak. }}$

\section{Quality of life/strength and difficulties}

The concept of quality of life is multi-dimensional and especially comprises physical, mental and social health (30). Both general and disease-specific questionnaires are used to describe health-related quality of life. Health-related quality of life, defined as a multidimensional construct pertaining to physical, emotional, mental, social and behavioural components of wellbeing and function as perceived by the patients and/ or observers (31), is assessed using the disease-specific Haemo-QoL (32) as well as the KINDL (33), a more generic tool for the assessment of quality of life. Furthermore, the difficulties in the areas of mood, concentration, behaviour and interaction with others are reflected by the use of the strength and difficulties questionnaire (SDQ, 34). 


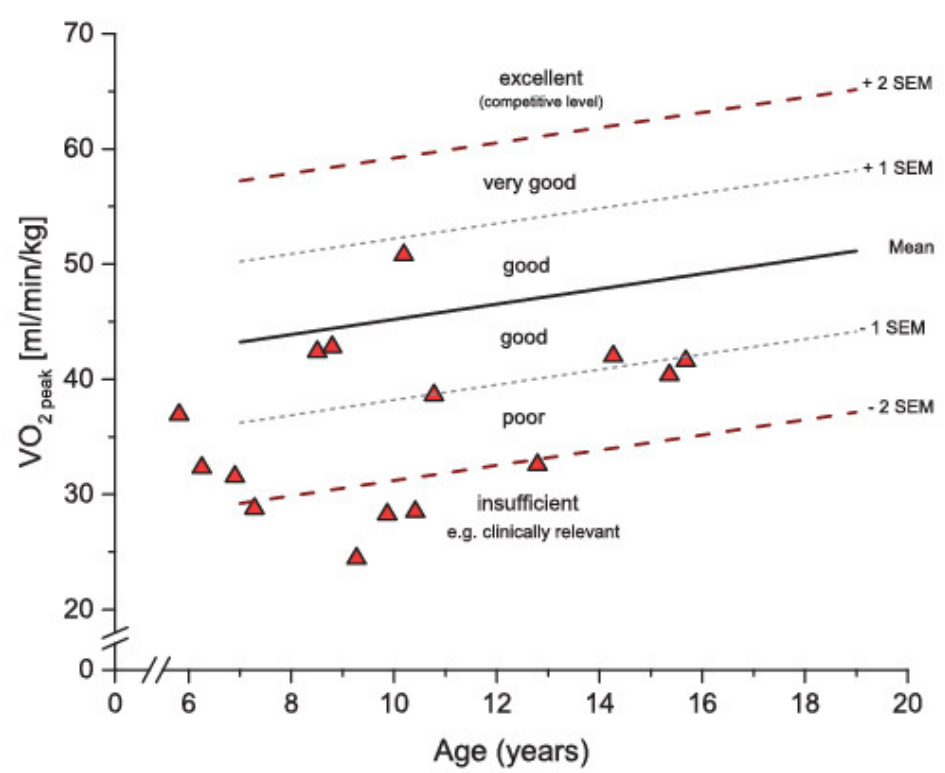

Fig. 5 Peak oxygen uptake $\left(\mathrm{VO}_{2}\right.$ Peak $\left.; \mathrm{ml} \mathrm{kg}^{-1} \mathrm{~min}^{-1}\right)$ during cardiopulmonary exercise test of the examined patients. The lines show the age-adjusted mean value (solid line) and the standard error of estimation (dashed lines) calculated via regression equations derived from Ten Harkel et al. (29).

\section{The annual bleeding rate}

The annual bleeding rate $(\mathrm{ABR})$ is calculated from the medical records and the patient's diary as the number of bleeding events per year. For the longitudinal assessment the $A B R$ is calculated as the number of bleeding events in the current year multiplied by 365 days and divided by the actual number of days the intervention period has lasted up to the date of examination. Based on these recordings soft tissue/muscle bleedings and joint bleedings are recognised separately. More severe bleedings were treated at the centre; less severe bleedings were treated at home. There was one patient with haemophilic arthropathy. With this finding of chronic joint involvement, he received intensified prophylaxis. Sonography and magnetic resonance imaging (MRI) serve as imaging tools used for diagnosis. There were no patients with inhibitors.

\section{Recording physical activity}

Form, duration, frequency and intensity of certain physical activity habits are documented over the previous year to evaluate the activity behaviour of the young hae- mophiliacs using a proxy report by the parents for the children under the age of 10 and by using interview-guided self-report for children and adolescents older than 10 years.

\section{Recommendations for physical education in school}

Each report of results includes recommendations for physical education in school that should be motivation and support for parents, teachers and training supervisors in finding ways to enabling children and adolescents with haemophilia to participate in sports and leisure activities within their individual abilities. Recommended exercises and sport disciplines are based on curricula on physical education of the individual federal states. The proposal follows the traffic light system - green for suitable, amber for suitable with some reservation and red for unsuitable.

\section{Physical activity annual meeting}

In addition to the individual tests described above performed during the examinations, a "Health and Physical Activity annual meeting" is held in Jena once a year as a day of fun, games and sports for children and adolescents with haemophilia and their families. This gathering generally serves to provide information about benefits and harm along with opportunities and limits of physical activity and to convey the joy of spontaneous guided movement through games, sports and physical activity with others. Participants can share experiences, meet new acquaintances, obtain answers to individual questions during a haemostaseological, sports medical health consultation, and make an appointment for a comprehensive examination as a part of this project.

\section{Statistical analyses}

Statistical analyses were performed using SPSS-22.0 software. All dependent parameters were tested for normal distribution using the Shapiro-Wilk test. For comparison of the differences in HJHS, ABR and AJBR before and after intervention the Wilcoxon sign test was used. Statistical difference between the two time points regarding endurance, strength and posturographic parameters were tested using $\mathrm{t}$-test for dependent samples. The significance level was defined as $p<0.05$.

\section{Results}

At the current stage of the study, cross-sectional and partly longitudinal data could be analysed. The main anthropometric and clinical characteristics are summarized (> Tab. 1).

Since the start of this project 15 children and adolescents (11 haemophilia A, 4 haemophilia B; 10 severe, 3 moderate, 2 mild) with a mean age of $9.2 \pm 3.4$ years were examined. In all, $73 \%$ of the examined patients use prophylaxis replacement therapy.

One child was classified as being overweight. This result is also reflected in the body fat percentage calculated via skinfoldthickness (see also $>$ Fig. 1 and $>$ Fig. 2).

There were comparatively good results of joint situation and coordination of the patients tested within this study. The total HJHS ranged from 0 to 9 with a median score of 2.0 (IQR 2-6). Only in three boys 
Tab. 1 Selected anthropometrical and some clinical data of the patients $(n=15)$ assessed in the pilot study.

\begin{tabular}{|c|c|c|c|}
\hline \multicolumn{2}{|l|}{ parameter } & \multirow{2}{*}{$\begin{array}{c}\text { mean } \pm \text { SD } \\
9.2 \pm 3.4 \\
136 \pm 21 \\
36.6 \pm 16.4 \\
18.9 \pm 3.4 \\
21 \pm 5\end{array}$} & \multirow{2}{*}{$\begin{array}{c}\text { range } \\
6-16 \\
114-177 \\
19.8-65.0 \\
14.7-27.8 \\
13-33\end{array}$} \\
\hline anthropometric data & $\begin{array}{l}\text { age [years] } \\
\text { body height }[\mathrm{cm}] \\
\text { body mass }[\mathrm{kg}] \\
\text { body mass index } \\
\text { body fat }[\%]\end{array}$ & & \\
\hline \multicolumn{2}{|c|}{ no. of soft tissue and joint bleedings (last year) } & $3.8 \pm 5.7$ & $0-22$ \\
\hline \multirow{2}{*}{$\begin{array}{l}\text { no. of treatment infusions (per } \\
\text { week); regime }\end{array}$} & "on-demand" & \multicolumn{2}{|l|}{ not available } \\
\hline & "prophylaxis" & $2.7 \pm 0.5$ & $2-3$ \\
\hline
\end{tabular}

(aged 10 years and older) the score was outside the range from 0 to 6 , which describes a normal joint condition according to Feldman et al. 2011 (19). The slightly elevated joint scores were caused by acute swelling of the knee or ankle joints, crepitus in motion, and abnormality in single skills of global gait. In no patient a reduced range of joint motion as well as marked muscle atrophy could be observed. Except in two cases for example the Stability Index, measured by posturography was within the normal range ( $\triangleright$ Fig. 4 ).

Regarding the endurance performance, with a mean $\mathrm{VO}_{2 \text { peak }}$ of $36.7 \mathrm{ml} \mathrm{kg} \mathrm{min}^{-1}$ the data of the initial measurement showed a poor aerobic capacity compared with the age- and gender-specific reference values (29). Three boys had values even below the lower $95 \%$ confidence limit of the reference dataset indicating considerable deficits in aerobic capacity ( $>$ Fig. 5).

The median ABR was about two bleedings per year. The calculated annual joint bleeding rate (AJBR) was about one bleeding a year. Around two-thirds of the bleeding events were soft-tissue and muscle bleedings, joint bleedings represented one third. Most frequently affected were joints of the knee, ankle and elbow. After the intervention, first data of patients measured twice showed a slight but non-significant reduction of the ABR. The AJBR remained almost unchanged.

The majority of the children and adolescents tested within this project participated in school sport, however, $40 \%$ were partially exempted. The amount of physical activity in school and leisure time was about less than three hours a week in $54 \%$ of all examined patients. Five patients were members in a sports club. Three of them were active in a swimming association. One played table tennis regularly. Only two of all patients used physiotherapy, namely water therapy or therapeutic climbing.

In nine cases, first long-term dataevaluation was carried out regarding patients that were examined two times or more. After the intervention the $\mathrm{ABR}$ showed a slight reduction (median 1.4; IQR $0-4)$, the AJBR remained almost unchanged (median 1.2, IQR 0-2). No significant difference could be detected between the two measuring dates $(\mathrm{p}>0.05)$.

After one-year intervention, four of nine patients showed lower scores, three unchanged and two patients higher scores compared to pre-measurement. With the median HJHS of 0 (IQR 0-2) after the intervention there was no significant difference compared to the beginning of the study (HJHS 2.0, IQR 0-3; p > 0.05).

The $\mathrm{VO}_{2 \text { peak }}$ and the Ventilatory Threshold (both normalized to body mass) increased by $13 \pm 10 \%$ resp. $29 \% \pm 33 \%$ after intervention of one year. These differences were statistically relevant for $\mathrm{VO}_{2 \text { peak }}(\mathrm{p}<$ $0.05)$ whereas only a trend was observed for the Ventilatory Threshold ( $\mathrm{p}<0.08)$.

Also the maximal isometric muscular strength as measured by the knee extensors and knee flexors increased significantly for both legs $(\mathrm{p}<0.05)$. No intervention effects were observed for the Stability Index of posturographic assessment $(\mathrm{p}>0.05)$.

\section{Discussion and conclusion}

The purpose of the presented project was to allow for a healthy childhood in haemophi-
Tab. 2 Clinical parameters of the patients $(n=15)$ assessed in the pilot study.

\begin{tabular}{|l|l|r|r|}
\hline \multicolumn{2}{|l|}{ clinical parameters } & n & \% \\
\hline $\begin{array}{l}\text { type of } \\
\text { haemophilia }\end{array}$ & A & 11 & 72.3 \\
\hline severity level & mild & 4 & 26.7 \\
\hline of haemophilia & moderate & 3 & 13.3 \\
\cline { 2 - 4 } & severe & 10 & 66.7 \\
\hline treatment & on-demand & 4 & 26.7 \\
\hline regime & prophylaxis & 11 & 73.3 \\
\hline haemophilic & yes & 1 & 6.7 \\
\hline arthropathy & no & 14 & 93.3 \\
\hline haemarthros & 0 & 6 & 40.0 \\
\hline (last year) & $<5$ & 7 & 46.7 \\
\hline & $5-11$ & 1 & 6.7 \\
\hline & $>11$ & 1 & 6.7 \\
\hline & yes & 9 & 60.0 \\
\hline school sport & partially & 6 & 40.0 \\
\hline exempted & no & 0 & 0 \\
\hline
\end{tabular}

* knee and/or ankle

liacs with an emphasis on physical activity, nutrition, and life skills. Therefore specific health promoting activities were offered to all patients of the Haemophilia treatment centre Jena. The patients examined until now form a representative sample of a paediatric haemophilic population, according to form and severity of disease.

A relatively homogeneous age group was examined. The children included mainly were in nursery and primary school. Therefore, differentiated evaluations and analyses between different age groups were not possible until now.

The anthropometrical data Body Mass Index and body fatness showed that a large proportion of the examined patients were within a normal age-adjusted reference range. The relative share of overweight was thus less than described prevalence of $13-30 \%$ among children with haemophilia in the literature $(11,35)$.

The observation that patients with HJHS scores $\geq 6$ were aged 10 years or older is consistent to findings, which state an increase of the HJHS with rising age with equal treatment strategy $(36,37)$. During 
the intervention period there could be recorded a maintenance and in some patients an improvement of the joint situation.

The recorded bleeding rate is also in the range described for larger samples of children with severe haemophilia under prophylaxis therapy and different levels of patient activity (41).

Despite a further increase of physical activity (especially by increased active participation in school sports as well as in leisure sport), during the reference period there was no increase of bleeding events in comparison to the previous year.

On the assumption that a continuous prophylactic substitution treatment with factor concentrates compared to a substitution on demand preserves a better joint situation and possibly increased physical activity, the body composition can be positively influenced, too.

There is a decreased aerobic capacity for children and adolescents as other studies showed $(6,13)$. This could be confirmed by our data. The values were at the lower boundaries of the range that is essential for a good health development of male children and adolescents (38-40). Notable improvements of the aerobic capacity could be achieved between pre- and postmeasurement (increase from $80 \%$ to $88 \%$ of age and gender predicted reference values) - which were even beyond the developmental increase. We recommend being physically active in a regular manner in an early stage.

In summary, conception and practical implementation of the project as a combination of functional prevention diagnostics and individual health counselling can be a practical approach to improve patient's health knowledge, self-competence and physical fitness.

Used methods during the routine examinations are practicable. The regularly demand for examination appointments and health clinic as well as the positive feedback on the part of the concerned and their relatives show a growing level of attention and interest being given to the project's offerings. The close cooperation between the Department of Sports Medicine and Health Promotion and the haematological outpatient unit of the Clinic for Children and Youth Medicine has been proven successful.

Especially preschool children and children who are just starting school took up such offers. In these two phases children have first sports education contact. The parents' interest was to get information about the physical fitness of their child and in respect to sports education to facilitate participation in various activities for the child. The recommendations for school sports increase the safety for all those involved - child, parents and sports teachers.

Based on the results during the routine sports-medical examinations important considerations can be drawn concerning the basic motor abilities and skills, which may modify the treating physician's recommendations for his patient. The "Health and Physical Activity annual meeting" has become a highlight that is well accepted by the children and adolescents and their relatives not only for the area of Thuringia but also for interested people and experts of other regions. This event provides a perfect setting for improving health knowledge, self-competence and physical fitness - through play, sport and fun. We plan further cooperation with other haemophilia treatment centres. A financial subsidy from health insurances or government to improve general health or to make inclusion possible may be necessary steps for the future.

Although the presented results of this model project are based on a low sample size and the initial interpretation of the longitudinal data could only be evaluated by feedbacks and personal ratings of the patients and families, the approach seems promising. First positive effects are already noticeable. For reliable scientific statements about the impact of the presented approach, extended longitudinal data will be necessary.

\section{Acknowledgments}

The authors thank Kerstin Weitnauer, Sylvia Marcik, and Sandra Fuchs for assistance in appointment coordination and delivering clinical findings as well as Rami Abou-Hamdan, Birgit Tauch, and Dr. Hans-Josef Müller for organizing and performing exercise tests.

\section{Conflict of interest}

The authors declare that they have no conflict of interest.

\section{References}

1. Gabriel HW. Leistungsoptimierung in der sportmedizinischen Gesundheitssprechstunde. . In: Baumbach-Knopf C, Achatz J, Knoepffler N, editors. Facetten der Ethik. 15. Würzburg: Königshausen \& Neumann; 2013. p. 141-60.

2. Rieger H-M. Gesundheit - Erkundungen zu einem menschenangemessenen Konzept. Leipzig: Evangelische Verlagsanstalt; 2013.

3. Blair SN, Kampert JB, Kohl HW et al. Influences of cardiorespiratory fitness and other precursors on cardiovascular disease and all-cause mortality in men and women. JAMA 1996; 276: 205-210.

4. Helmrich SP, Ragland DR, Leung RW, Paffenbarger RS. Physical activity and reduced occurrence of non-insulin-dependent diabetes mellitus. N Engl J Med 1991; 325: 147-152.

5. Haskell WL. J.B. Wolffe Memorial Lecture. Health consequences of physical activity: understanding and challenges regarding dose-response. Med Sci Sports Exerc 1994; 26: 649-660.

6. Schoenmakers MA, Gulmans VA, Helders PJ, van den Berg HM. Motor performance and disability in Dutch children with haemophilia: a comparison with their healthy peers. Haemophilia 2001; 7: 293-298.

7. Manco-Johnson MJ, Riske B, Kasper CK. Advances in care of children with hemophilia. Semin Thromb Hemost 2003; 29: 585-594.

8. Dolan G. The challenge of an ageing haemophilic population. Haemophilia 2010; 16 (Suppl 5): 11-16.

9. Wittmeier K, Mulder K. Enhancing lifestyle for individuals with haemophilia through physical activity and exercise: the role of physiotherapy Haemophilia 2007; 13 (Suppl 2): 31-37.

10. Mulder K, Cassis F, Seuser DR et al. Risks and benefits of sports and fitness activities for people with haemophilia. Haemophilia 2004; 10 (Suppl 4): 161-163.

11. Engelbert RH, Plantinga M, Van der Net J et al. Aerobic capacity in children with hemophilia. J Pediatr 2008; 152: 833-838.

12. Egan B, Eldridge B, Barnes C, Wolfe R. Are boys with severe haemophilia as physically active as the normal population? Haemophilia 2006; 12 (Suppl 2): 103-106.

13. Van der Net J, Vos RC, Engelbert RH et al. Physical fitness, functional ability and quality of life in children with severe haemophilia: a pilot study. Haemophilia 2006; 12: 494-499.

14. Falk B, Portal S, Tiktinsky R et al. Bone properties and muscle strength of young haemophilia patients. Haemophilia 2005; 11: 380-386.

15. Seuser A, Kurme A, Trunz E et al. Fit for Life - Fitness Levels of Young Hemophiliacs Today. In: Scharrer I, Schramm W, editors. $34^{\text {th }}$ Hemophilia Symposium Hamburg 2003. 34. Berlin, Heidelberg: Springer-Verlag; 2005. p. 232-7.

16. Plachta-Danielzik S, Gehrke MI, Kehden B et al. Body fat percentiles for German children and adolescents. Obesity facts 2012; 5: 77-90. 
17. Kromeyer-Hauschild K, Wabitsch M, Kunze D et al. Perzentile für den Body-mass- Index für das Kindes- und Jugend- alter unter Heranziehung verschiedener deutscher Stichproben. Monatsschr Kinderheilkd 2001; 149: 807-818.

18. AGA. Arbeitsgemeinschaft Adipositas im Kindesund Jugendalter: (S2-) Leitlinie 2010 der AGA zur Therapie der Adipositas im Kindes- und Jugendalter 2010 [24.05.2011].www.a-g-a.de/Leitlinie.

19. Feldman BM, Funk SM, Bergstrom BM et al. Validation of a new pediatric joint scoring system from the International Hemophilia Prophylaxis Study Group: Validity of the hemophilia joint health score. Arthritis care \& research 2011;63: 223-230.

20. Hilliard P, Funk S, Zourikian N, Bergstrom BM, Bradley CS, McLimont M, et al. Hemophilia joint health score reliability study. Haemophilia 2006; 12: 518-525.

21. Kohen-Raz R. Application of tetra-ataxiametric posturography in clinical and developmental diag nosis. Percept Mot Skills 1991; 73: 635-656.

22. Hilberg T, Herbsleb M, Gabriel HHW et al. Proprioception and isometric muscular strength in haemophilic subjects. Haemophilia 2001; 7: 582-588.

23. Krishnamurthy R, Mohanty P, Kumar D, Niranjan S. Bleed frequency, proprioception and isometric muscle strength in haemophilic arthropathy. Haemophilia 2004; 10 (Suppl. 3): 132.

24. Seuser A, Kurme A, Wallny T et al. How to advise young hemophiliacs to find the right sport? A new and safe algorithm! Haemophilia 2004; 10: 104.

25. Stephensen D, Winter M. Defects in standing balance in children with severe haemophilia A. Haemophilia 2002; 8: 479.
26. Schwesig R, Lauenroth A, Müller A et al. Parametrisierung posturaler Subsysteme mit Posturografie. Manuelle Medizin 2006; 44: 376-384.

27. Herbsleb M, Tutzschke R, Czepa D et al. Isometrische Maximalkraftmessungen der Quadrizepsmuskulatur. Durchfuhrbarkeit und Reliabilitat bei Patienten mit Hamophilie. Hämostaseologie 2010; 30 (Suppl 1): S97-S103.

28. Godfrey S. Exercise testing in children. Applications in health and disease. Philadelphia: Saunders; 1974.

29. Ten Harkel AD, Takken T, Van Osch-Gevers M, Helbing WA. Normal values for cardiopulmonary exercise testing in children. Eur J Cardiovasc Prev Rehabil 2011; 18: 48-54.

30. Radoschewski M. Gesundheitsbezogene Lebensqualit ̈̈t - Konzepte und Maße. Bundesgesundheitsbl - Gesundheitsforsch - Gesundheitsschutz 2000; 43: 165-!89.

31. Bullinger M. Quality-of-Life - Definition, Conceptualization and Implications - a Methodologists View. Theor Surg 1991; 6: 143-!\$8.

32. von Mackensen S, Bullinger M, Haemo-Qo LG. Development and testing of an instrument to assess the Quality of Life of Children with Haemophilia in Europe (Haemo-QoL). Haemophilia 2004; 10 (Suppl 1): 17-25.

33. Ravens-Sieberer U, Bullinger M. Assessing healthrelated quality of life in chronically ill children with the German KINDL: first psychometric and content analytical results. Qual Life Res 1998; 7: 399-407.

34. Goodman R. The Strengths and Difficulties Questionnaire: a research note. J Child Psychol Psychiatry 1997; 38: 581-586.
35. Douma-van Riet DC, Engelbert RH, van Genderen FR et al. Physical fitness in children with haemophilia and the effect of overweight. Haemophilia 2009; 15: 519-527.

36. Bladen M, Main E, Hubert $\mathrm{N}$ et al. Can the Haemophilia Joint Health Score (HJHS) identify differences in joint status in boys with severe haemophilia receiving prophylaxis? Haemophilia 2010; 16 (Suppl 4): 113.

37. Saulyte Trakymiene S, Ingerslev J, Rageliene L. Utility of the Haemophilia Joint Health Score in study of episodically treated boys with severe haemophilia A and B in Lithuania. Haemophilia 2010; 16: 479-486.

38. Lobelo F, Pate RR, Dowda M et al. Validity of cardiorespiratory fitness criterion-referenced standards for adolescents. Med Sci Sports Exerc 2009; 41: 1222-1229.

39. Cureton KJ, Warren GL. Criterion-referenced standards for youth health-related fitness tests: a tutorial. Res Q Exerc Sport 1990; 61: 7-19.

40. Blair SN, Clark DB, Cureton KJ, Powell KE. Exercise and fitness in childhood: Implications for a lifetime of health. In: Gisolfi CV, Lamb DL, editors. Perspectives in exercise science and sports medicine: Youth, exercise and sport. Youth, exercise and sport. Indianapolis: Benchmark Press; 1989. p. 401-22.

41. Broderick CR, Herbert RD, Latimer J et al. Association between physical activity and risk of bleeding in children with hemophilia. Jama-J Am Med Assoc 2012; 308: 1452-1459. 